\title{
Aptitude Test's Predictive Ability for Academic Success in Psychology Student
}

\author{
Farida Agus Setiawati \\ ${ }^{1}$ Department of Psychology, Universitas Negeri Yogyakarta, \\ Jl. Colombo No. 1 Karang Malang Sleman, Yogyakarta \\ farida_as@uny.ac.id
}

\begin{abstract}
The developments that occur in psychological measurement have an effect on the development of the quality of the tests used. Differential Aptitude Test (DAT) is a psychological test commonly used to measure a person's aptitude. Aptitude measurement needs to be proven on the success of post-aptitude test studies. Therefore, this study aims to examine: (1) the predictive validity of differential aptitude tests in predicting academic success in the context of psychology study programs, and (2) which subtests are influential in predicting the success of studies in psychology study programs. Data collection was carried out using test techniques and documentation techniques. The research subjects were 148 students majoring in psychology at Yogyakarta State University. The data obtained were then analyzed using multiple linear regression analysis techniques, where the subtest scores on the DAT were treated as predictors and the Grade Point Average scores were treated as the dependent variable. Based on the results of the analysis, it can be concluded that: (1) the DAT test can predict the success of the study in the psychology study program; and (2) the subtest in DAT that has the most influence in predicting the success of the study in the psychology study program is the verbal subtest and the numerical subtest.
\end{abstract}

Keywords: academic success, differential aptitude test, predictive validity

\section{Introduction}

Psychology is often defined as the study of the human mind. In studying it, the object studied in psychology cannot be seen directly because of its abstract nature, but human mind manifests and expresses through behavior. In expanding its' body of science, psychology develops itself in various fields, one of which is in the field of measurement of the psychological aspect, or commonly known as psychometrics. The scope of psychometrics includes the development of test theories and models as well as developing the basics for evaluating the quality of the tests used. At the application stage, theories in psychometrics provide a fundamental foundation in the design and development of psychological tests so that test construction methods can develop and produce various forms of valid and reliable psychological tests. Thus, with the development of the science of psychology, the science of psychometrics has also developed in the development of various forms of psychological measuring instruments and their analysis methods.

Judging from the attributes of human psychological characteristics, measurements in the field of psychology can be divided into various forms: (1) intelligence tests are tests to determine general human abilities, (2) aptitude tests are tests to determine specific human abilities, (3) preference tests are tests to explore one's preference or interest regarding a certain field, and (4) a personality test is a test to determine a person's traits, habits or tendencies in certain aspects. Each of these psychological attributes can be detected using various forms of psychological testing.

One form of psychological test used to measure human talent is the Differential 
Aptitude Test (DAT). This test was first compiled in 1947 by George K. Bennet, Harold G. Seashore, and Alexander G. Wesman (Bennett, Seashore, \& Wesman, 1948). This test is presented in the form of a series of tests or what is called a multiple aptitude series consisting of seven subtests, namely: (1) verbal reasoning (VR) which measures the ability to think and solve problems related to verbal concepts or words, (2) numerical ability ( $\mathrm{na}$ ) which measures the ability to think with numbers, especially related to arithmetic skills, (3) abstract reasoning (ar) which measures nonverbal reasoning skills such as understanding logical relationships, (4) clerical speed and accuracy (csa) which measures the response to tasks or jobs that involve the speed of perception and the speed of response to the combination of letters and numbers, (5) mechanical reasoning $(\mathrm{mr})$ which measures the power of reasoning in the field of mechanical work, (6) space relations (sr) which measures the ability to think visually from geometric shapes, and (7) language usage which consists of spelling and sentences, which measure general understanding in language.

Differential aptitude tests are included as multiple aptitude batteries, which can be used to measure various abilities, such as numerical abilities, spatial vision, numerical reasoning, and speed and accuracy in perception. Anastasi (1997) states that in addition to DAT, Intelligence Structural Test (IST), Flanagan Aptitude Classification Test (FACT), General Aptitude Test Battery (GATB) is also a multiple aptitude battery. The results of the multiple aptitude battery test are in the form of a profile number that describes the abilities, strengths, and weaknesses of a person. Talent test results differ from different forms of talent, but it is possible that only a few abilities can be revealed (Ruth, 1971). High talent scores, for example in mechanics and abstract subtests, can be interpreted that with further training, the individual will perform well as an engineer or in a related field of work (Marais, 2007).

In general, experts have agreed that talent is a natural ability, natural skills or talent (Mankar \& Chavan, 2013). It is further emphasized that talent can be identified from the start through a series of tests, one of which is by using DAT. In DAT, the detection of talent uses a series of tests that are used for a specific purpose with a predetermined time. Specifically, a series of independent DAT tests are used by individuals to: (1) help choose majors or study programs and career development based on their strengths and weaknesses, (2) understand why individuals or students look high or have low scores. for certain subjects or courses, (3) giving consideration to new career options, and (4) as a basis for consideration in changing or achieving other or higher career and educational aspirations. From this explanation, it can be concluded that DAT can be used as a predictor of individual talent that can be used as a guide for decision making related to self-development in education and career choices. Thus it can be said that the aptitude test is one aspect that can be used to predict future performance in several activities such as academic success (Aiken, 1988; Gronlund, 1981; Sax, 1980).

One of the functions of the aptitude test is to predict the success of individuals in the field of education, one of which is studying psychology. A psychology student is guided to gain core competencies: (1) mastering the discipline of psychology as a whole, (2) knowing and understanding aspects of ethics, law, to professional psychological practice, (3) compiling and using psychometric tools and interpreting the results of their measurements, 4) carry out activities to restore, maintain, or improve cognitive function of individuals or groups through counseling services, (5) perform critical analysis in terms of evaluating and applying findings from scientific publications to help clients, (6) 


\section{Aptitude Test's Predictive Ability \\ Farida Agus Setiawati}

conveying, assessing, and interpreting information orally and in writing to interact with various client groups and other professional groups, (7) able to adapt to different client backgrounds (for example physical disabilities, beliefs, language, sexual orientation, etc.), and (8) able to provide good service to clients of all ages (Australian Psychology Accreditation Council, 2010; New Zealand Psychologist Board, 2011). Based on this description, it can be seen that to be able to successfully study in the field of psychology, certain basic abilities must be present in students. This is in line with Chatterjee's opinion (Raza \& Shah, 2011) which states that aptitude tests play an important role in determining the future of student education because aptitude tests measure the overall performance of students in various areas of mental ability.

Talent is a special ability that exists in an individual which is formed from his own experience and not from special treatments or learning processes. The aptitude test is a tool for measuring a sample of behavior that can be used as an indicator for other behaviors in the future. Therefore, the validity of the aptitude test lies in the ability of the test to predict a person's performance in the future (predictive validity). Validity itself can be defined as a level that states that a measuring instrument is in accordance with what is being measured (Nunnaly, 1978: 132, Allen \& Yen, 1979: 97). Predictive validity is included in validity based on criteria (criterion-related validity). The predictive validation procedure takes a long time and costs a lot because this procedure is basically not a job that is considered complete after a single analysis, but rather takes place continuously in developing tests as a good predictor (Mardapi, 2007).

The ability to predict a test is very important. The more precise and accurate a test is in predicting student success in achieving learning success, the better the quality of the test. Various studies to determine the psychometric characteristics of tests, especially in relation to the predictive validity of aptitude tests, have been researched by experts since ancient times until now. Most of the studies on predictive validity use linear models with correlation and multiple regression methods as methods of analysis (Linn, 1984). The size of the estimated predictive validity of an instrument is described by the correlation coefficient between the predictors and these criteria. If this coefficient is obtained from a group of individuals who are a representative sample, then a measuring instrument whose validity has been tested will have a predictive function that is very useful in the procedure for measuring instruments in the future.

One of the criteria for student's academic success can be seen from their grade point average (GPA). Research conducted by Njienhuis, Evers, \& Mur (2000) which examines the validity of DAT in immigrant children in the Netherlands shows that DAT is proven to be a tool that can be used to predict individual abilities in certain fields, such as mathematics. A slightly more complex study was conducted by Curabay (2016) by conducting a metaanalysis of 48 studies on predictive validity. The results of the study concluded that there was a significant positive correlation $(\mathrm{r}=0.36)$ between the SAT scores and the student's GPA. Similar research results were also obtained by Mankar \& Chavan (2013) with an exploratory study which showed a high correlation between personal characteristics and student talent. This exciting result is also reinforced by Stickler's (2007) study which states that SAT scores are able to predict 20 to $30 \%$ of student success in college.

Research on each talent subtest has also been researched by experts. In 2011, Shea, Lubinski, \& Benbow conducted a 20 year longitudinal study of the importance of assessing spatial abilities in intellectually gifted subjects ranging from 13 years to 33 years of age. This study looks at the 


\section{Aptitude Test's Predictive Ability \\ Farida Agus Setiawati}

development of the educational process carried out to the chosen job.

Based on the description above, this study aims to examine: (1) to what extent the differential aptitude test can predict the success of student studies in the psychology study program, and (2) which talent subtests are influential in predicting the success of studies in the psychology study program.

\section{Methods}

The study population was all students majoring in psychology, Yogyakarta State University, Academic Year 2015 to 2017, totaling 235 people. The research sample of 148 students was obtained by means of cluster random sampling by randomizing the population based on the class. The number of samples was determined using the formula from Slovin.

This research is a quantitative study using data in the form of aptitude test results and GPA. The data was collected through test techniques and documentation techniques. The test technique using the Differential Aptitude Test (DAT) instrument was used to obtain the aptitude test scores for each student, while the documentation technique was used to obtain the Grade Point Average (GPA) in the study sample.

The research variables consisted of the independent variable (predictor) and the dependent variable (criteria). What functions as a predictor is the DAT score which represents the talents of the research subject which consists of six subtests namely verbal (X1), numerical (X2), abstract (X3), spatial relation (X4), mechanical (X5), and clerical (X6). ; Meanwhile, what serves as a criterion is the success of the study represented by the GPA in the first semester which has a range between $0.00-4.00$.

The data analysis technique used in this study is the multiple linear regression analysis technique with the help of the IBM SPSS 21 program. The output of the regression analysis will produce a correlation coefficient $(\mathrm{R})$ which indicates the predictive validity of DAT on student success, the coefficient of determination. (R2) which shows the magnitude of the influence (contribution) of DAT scores in predicting student academic success, as well as the correlation coefficient ( $r$ ) and significance (sig) of each subtest in DAT that can predict student academic success.

\section{Findings and Discussion}

Analysis used in the multiple regression test in this study is the Enter (default) method. This method analyzes the independent variables simultaneously without sorting the variables into one group in the regression equation (Sudarmanto, 2005). The following is an explanation of the research data:

Tabel 1. Descriptive Statistics

\begin{tabular}{lcccc}
\hline & Minimum & Maximum & Mean & Std. Deviation \\
\hline GPA & 2.71 & 3.86 & 3.4861 & 0.23179 \\
Verbal & 55.00 & 119.00 & 99.9839 & 14.95731 \\
Numeric & 28.00 & 115.00 & 100.0000 & 15.03875 \\
Abstract & 29.00 & 122.00 & 99.9516 & 15.00648 \\
Space Relation & 46.00 & 126.00 & 100.0000 & 15.07359 \\
Mechanical & 67.00 & 119.00 & 100.0968 & 14.89494 \\
Clerical & 51.00 & 110.00 & 100.0161 & 15.06107 \\
\hline
\end{tabular}




\section{Aptitude Test's Predictive Ability \\ Farida Agus Setiawati}

Table 1 shows the descriptive statistics that contain the maximum value, minimum value, mean score, and standard deviation for each variable. Based on this table, it is known that the average GPA of the research sample is 3,486, while the mean score of the aptitude test results on the six subtests tends to be the same, namely at a score of 100 with a standard deviation of 15 . The similarity of the mean score and standard deviation is because before entering the analysis stage, the raw score data first undergo a transformation. Data transformation is one way to transform data into other forms so that the data has the expected distribution. The data transformation procedure makes it possible to perform the same mathematical operations on the original data, namely changing all data to keep the differences between data relatively constant. Data transformation needs to be done considering that each subtest has a different number of items so that it will produce different raw scores. This difference in raw scores results in differences in the range of scores which in turn result in subtest scores being unable to be compared on one scale. In addition to the mean and standard deviation, the results of descriptive statistics also show that the highest score of the psychology student aptitude test is on the spatial relation subtest, which is 119 , while the lowest score is in the numerical subtest, which is 28 .

Tabel 2. Anova

\begin{tabular}{llrrrrr}
\hline \multicolumn{1}{l}{ Model } & & Sum of & & & & \\
\hline 1 & Regression & 1.347 & 6 & 0.225 & 6.400 & 0.000 \\
& Residual & 1.930 & 55 & 0.035 & & \\
& Total & 3.277 & 61 & & & \\
\hline
\end{tabular}

Table 2 presents the results of the simultaneous regression analysis through the ANOVA test. This test is used to determine whether the independent variable $(\mathrm{X})$ together has a significant effect on the dependent variable $(\mathrm{Y})$ or to find out whether the regression model can be used to predict the dependent variable or not. The significance of the test results shows that the value obtained is $\mathrm{F}=6.4, \mathrm{p}$
$=0.000$, so that the null hypothesis $(\mathrm{H} 0)$ tested in this study is not proven. Based on this, it can be concluded that there is a significant effect of the scores of each DAT subtest together in predicting the academic success of psychology study program students or in general it can be said that the resulting regression model can be used to predict the academic success of psychology study program students.

Tabel 3. Model Summary

\begin{tabular}{llrrr}
\hline Model & R & R Square & Adjusted R Square & Std. Error of the Estimate \\
\hline 1 & $0.641^{\mathrm{a}}$ & 0.411 & 0.347 & 0.18732 \\
\hline
\end{tabular}

Table 3 contains information about the predictive validity of aptitude tests on the success of psychology student studies as reflected in the price of the multiple correlation coefficient (R). This coefficient shows how much the proportion of the variance of the dependent variable can be explained by the independent variable or its predictor. Based on the table above, it can be seen 


\section{Aptitude Test's Predictive Ability \\ Farida Agus Setiawati}

that the resulting multiple correlation coefficient is 0.641 . This shows that the relationship between the results of the aptitude subtest on the success of psychology student studies is a strong and positive relationship.

Tabel 4. Coefficients

\begin{tabular}{|c|c|c|c|c|c|c|}
\hline & \multicolumn{2}{|c|}{$\begin{array}{c}\text { Unstandardized } \\
\text { Coefficients }\end{array}$} & \multirow{2}{*}{$\begin{array}{c}\text { Standardized } \\
\text { Coefficients } \\
\text { Beta } \\
\end{array}$} & \multirow[b]{2}{*}{$\mathrm{T}$} & \multirow[b]{2}{*}{ Sig. } & \multirow[b]{2}{*}{ Partial } \\
\hline & B & Std. Error & & & & \\
\hline (Constant) & 2.437 & 0.337 & & 7.233 & 0.000 & \\
\hline Verbal & 0.006 & 0.002 & 0.390 & 3.689 & 0.001 & 0.445 \\
\hline Numeric & 0.005 & 0.002 & 0.322 & 2.720 & 0.009 & 0.344 \\
\hline Abstract & 0.000 & 0.002 & -0.020 & -0.173 & 0.863 & -0.023 \\
\hline Space & -0.004 & 0.002 & -0.258 & -2.475 & 0.016 & -0.317 \\
\hline Relation & & & & & & \\
\hline Mechanical & 0.000 & 0.002 & 0.015 & 0.137 & 0.892 & 0.018 \\
\hline Clerical & 0.004 & 0.002 & 0.230 & 2.138 & 0.037 & 0.277 \\
\hline
\end{tabular}

Table 4 shows the results of the analysis of each subtest separately or partially through the $t$ test. If the $t$ value probability (shown in Sig.) Is smaller than the error rate $(\alpha) 0.01$, it can be said that the independent variable partially has a significant effect on the dependent variable, and vice versa. Based on the table above, it can be seen that the verbal, numerical, and spatial relation subtests have a regression weighted significance value below 0.01 , so the null hypothesis (H0) tested in this study is also not proven. However, if we look further, it turns out that the t-count statistic and the regression coefficient (weight) on the spatial relation subtest have a negative sign, so that the spatial relation subtest is not included in the regression equation. So, it can be concluded that partially, only verbal subtest and numerical subtest have a significant effect on the academic success of psychology study program students.

\section{Discussion}

There are two important parts that will be discussed in this section. namely: (1) analysis of the overall subtests in the
DAT instrument on the success of the study in the psychology study program, (2) the results of the analysis on the subtests in the DAT instrument which have been shown to significantly influence the success of studies in the psychology study program.

The results of the analysis in Table 2 show that the null hypothesis ( $\mathrm{H} 0$ ) is rejected so that it means that there is a significant effect of the scores of each DAT subtest simultaneously on the academic success (GPA) of psychology study program students, while the results of the analysis in Table 3 show that the score the predictive validity of DAT on the success of the study which is reflected in the price of the multiple correlation coefficient $(\mathrm{R})$ is in the high category. These results are in line with the research of Santosa (2013) which found the predictive validity of the Academic Potential Test on GPA of 0.368 with a significant contribution of $13.5 \%$.

The ability of DAT scores in predicting learning success of psychology study program students is supported by the data in Table 3. Standard Error of the Estimate (Table 3) which shows a measure of the number of errors in the regression 
model in predicting the $\mathrm{Y}$ value shows a number of 0.19812 . If you pay attention to the statistical descriptive analysis (Table 1), it can be seen that the standard deviation of the GPA is 0.23179 which is greater than the standard error estimate. Because the standard error estimate is smaller than the standard deviation of the GPA, it can be said that the regression model is good at acting as a predictor of learning success in the psychology study program.

In addition, the magnitude of the variance of the aptitude sub-test jointly from all variables $\mathrm{X}$ against $\mathrm{Y}$ can also be seen from the $\mathrm{R}$ square in Table 3.Because $\mathrm{R}$ square $=0.411$ it can be interpreted that the joint aptitude test contribution to the success of the study is $41.1 \%$ while The remaining $58.9 \%$ is contributed by other factors. Various studies state that academic success is not only supported by talent, but also influenced by many other aspects including interest, gender, family socio-economic conditions, parental education level, and environmental conditions (Fraser \& Killen. 2003; Hijazi \& Naqvi. 2006 ; Raza \& Shah. 2009; Akessa \& Dhufera. 2015; Dev. 2016).

Table 4 presents the results of the analysis of each subtest separately or partially through the $t$ test which is useful for seeing the regression equation in predicting the academic success of psychology study program students. Based on the table, it can be seen that only the verbal subtest constants (X1) and the numerical subtest (X2) have positive and significant regression weights, so the resulting regression equation:

$$
\mathrm{Y}=2.437+0.006 \mathrm{X} 1+0.005 \mathrm{X} 2
$$

The regression coefficient on both the verbal subtest and the numerical subtest are both positive, meaning that when the verbal and numerical subtest scores increase, the academic success (GPA) of the psychology study program students will also increase. Likewise, when the verbal and numerical subtest scores decrease, the academic success (GPA) of psychology study program students will also decrease. An increase in the verbal subtest score by $1 \%$ will increase the academic success by $0.0006 \%$ and vice versa, a decrease in the verbal subtest score by $1 \%$ will decrease the academic success by $0.0006 \%$.

As explained in the research results, the spatial relation subtest actually also has a smaller significance than the alpha, but the t-count statistic and the regression coefficient have a negative sign. This negative sign can be interpreted that there is a relationship that is best proportional to the meaning that the higher the spatial relation subtest score will actually make the academic success of psychology study program students lower. Based on these reasons, the spatial relation subtest is not included in the regression equation. Although only two of the six variables in the aptitude test have been shown to partially affect the success of student studies, the overall residual data generated from the multiple linear regression model has a normal distribution pattern. This can be proven in the results of the Normal PP Plot analysis as presented in Figure 1. The meaning of normality in the Normal PP Plot is as follows: if the distribution of points (plots) approaches or is dense on a straight line (diagonal) it can be said that (data) The residual is normally distributed, but if the distribution of the points is a diagonal line, the data is not normally distributed. 
Normal P-P Plot of Regression Standardized Residual

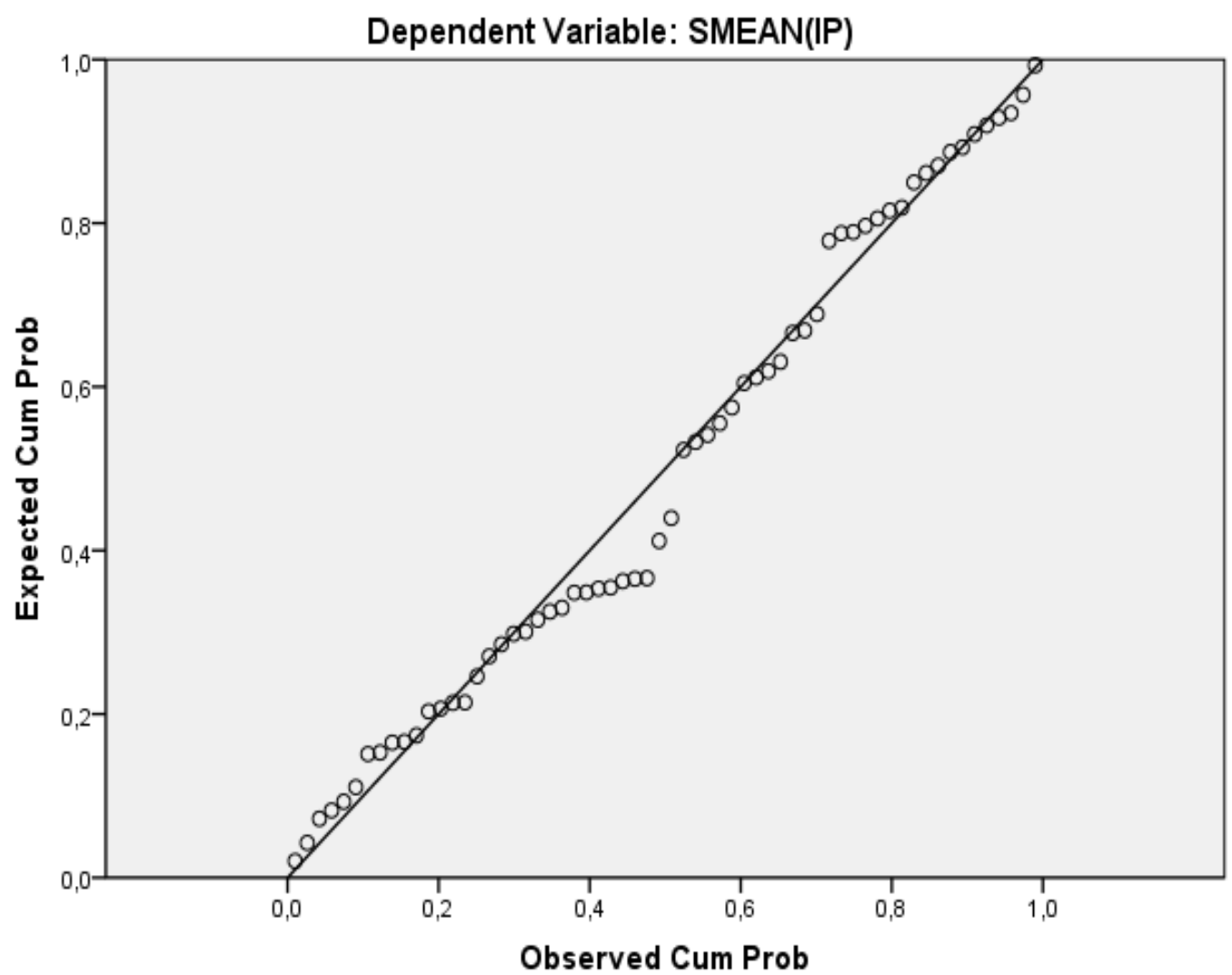

Figurer 1. Residual's Normality of the Multiple Linear Regression Model

The strength and weakness of the influence and the form of the relationship between verbal subtest and numerical subtest on the learning success of psychology study program students can also be interpreted from the value of the partial correlation coefficient. The partial correlation coefficient is used to determine the relationship between two variables in which the other variables that are considered influential are controlled or made fixed (as control variables). The correlation value (r) ranges from +1 to -1 , the closer the value to +1 or -1 means that the relationship between the two variables is getting stronger, on the other hand, the value close to 0 means that the relationship between the two variables is getting weaker. A positive value indicates a unidirectional relationship ( $\mathrm{X}$ increases, $\mathrm{Y}$ increases) and a negative value indicates an inverse relationship ( $\mathrm{X}$ increases then $\mathrm{Y}$ falls). Based on the results of the analysis, the partial correlation coefficient of verbal subtest and numerical subtest on learning success in the psychology study program was 0.445 and 0.344 , respectively, which indicated that there was a strong (moderate) and unidirectional (positive) relationship. This further strengthens the meaning of the relationship that occurs between the independent variables and the dependent variable such as the regression coefficient previously described, that is, if there is an increase in the score of the verbal subtest and the numerical subtest, then the success of the psychology study program students as reflected in their GPA will also increase.

The explanation above is based on the results of the analysis of the entire subtest contained in the DAT instrument, however, when the subtests which are proven to have no significant effect on the success of the study of psychology study program students are not included in the 
analysis process, the results of the analysis are slightly different. The results of the analysis in table 5 show that the verbal and numerical subtest simultaneously contributed $29.3 \%$. When linked with table 2, it can be concluded that other subtests (abstract, spatial relations, mechanics, and clerical) only contributed $11.8 \%$. Based on these data, it is evident that verbal and numerical subtests dominate in predicting the academic success of psychology students.

Tabel 5. Model Summary for Verbal dan Numerikal Subtest

\begin{tabular}{ccccc}
\hline Model & R & R Square & Adjusted R Square & Std. Error of the Estimate \\
\hline 1 & $0,542^{\mathrm{a}}$ & 0,293 & 0,269 & 0,19812 \\
\hline
\end{tabular}

a. Predictors: (Constant), SMEAN(numerikal), SMEAN(verbal)

b. Dependent Variable: IPK

The use of verbal and numerical tests as predictors of academic success has been applied for a long time. In the report on the results of the meta-analysis research conducted by Young (2001), it was explained that since 1959 the predictive ability of these two subtests was so popular that it was included as one of the components to be measured in the ACT (American College Testing) and SAT. The report also provides a table containing 29 studies that prove that verbal and numerical tests are good predictors. Including research conducted by Arbona \& Novy (1990), Baggaley (1974), Bridgeman. et.al (2000), Elliot \& Strenta (1988), Farver. et.al. (1975) and others.

Research conducted by Mankar \& Chavan (2013) also showed a significant relationship between the two subtests against the criteria, namely having a correlation coefficient of 0.543 and 0.406 , respectively. Furthermore, in the book DAT for Selection General Abilites Battery: Technical Manual and User Guide (2013) it is written that verbal and numerical abilities are indeed the basis for understanding lessons in school so that this ability is a predictor of success in the academic field. The combination of the two tests is often referred to as educational aptitude or better known as the scholastic test, where this test serves to measure the ability to complete scholastic tasks such as academic ability and the ability obtained from learning outcomes (reading books and teacher teaching). A person who has high scholastic ability is predicted to be able to complete assignments well in college and vice versa, someone whose scholastic ability is less is not recommended to continue education to the tertiary level. Based on this explanation, this study also proves that a good predictor of academic success is verbal ability and numerical ability. These results are reinforced by the opinion expressed by Oyetunde (in Ballado, Morales, \& Ortiz, 2014) which states that aptitude tests can be used to detect a series of a person's talents, but more specifically, the aptitude test contains a group of items that measure verbal ability and numerical abilities that can predict a person's performance in various educational programs.

The correlation coefficient on the mechanical and clerical subtests has a small partial correlation coefficient, namely 0.013 and 0.262 , respectively. Meanwhile, the abstract subtest and spatial relations have a negative spatial correlation coefficient, which is -0.020 and -0.308 , respectively. The dominance of the measured subtest from the results of the measurement of differential aptitude will indeed produce different results, in the 
field of psychology the subtest does not dominate, in other fields it may be different. Ruth (1971) stated that the clerical subtest can be a good predictor of the success of studies in business education, as well as the mechanical subtest will be a good predictor of the success of studies in vocational education. Ruth's research results are supported by a report written by Pearson Assessment (2009). This report contains descriptor of each capability related to the field it can support. High abstract ability is suitable for occupations related to mathematics, computer programming, science, and engineering; High clerical abilities suitable for work related to secretarial or administrative, computer programming, science and technology (especially those working in laboratories), law, finance, and accounting; high mechanical ability suitable for work fields related to mechanics, technicians, carpenters, machine operators, surveyors, electricians, and architects; as well as high space relations capabilities suitable for work fields related to architects, designers, dentists, and technicians. The dominance in the mastery of a subtest is very important to note. remembering to study a field requires different abilities.

\section{Conclusion}

Based on the results of the analysis, it can be concluded that:

1. The Differential Talent Test can predict the success of the study of psychology study program students

2. The amount of the variance of the overall contribution of the talent subtest to the success of the study is 0.411 or $41.1 \%$,

3. DAT subtests that have the most influence in predicting academic success in the psychology study program are the verbal subtest and the numerical subtest. The number of variants of verbal and numerical subtests in predicting academic success was $29.3 \%$.

The implications and suggestions based on the research results above are:

1. More extensive research is needed to see the prediction of successful studies in the field of psychology by looking at other aspects outside the aptitude test.

2. Research to test the validity of differential aptitude tests needs to be reviewed and developed from the various types of validity that exist.

3. Other influences beyond one's talents need to be reviewed to determine the factors of success in higher education in other study programs.

\section{References}

Aiken. L. R. (1988). Psychological testing and assessment ( $6^{\text {th }}$ Ed.). Boston: Allyn and Bacon. Inc.

Akessa. G. M.. \& Dhufera. A. G. (2015). Factors that influences students academic performance: a case of rift valley university. jimma. ethiopia. Journal of Education and Practice. 16 (22). 55-63.

Allen. M.J.. \& Yen. W.M. (1979). Introduction to measurement theory. California: Brooks/Cole Publishing Company Wardsworth. Inc.

Anastasi. A. (1997). Psychological testing (7th Ed). New Jersey: Prentice-Hall Inc.

Anderson. L.. \& Krathwohl. D.A. (2001). Taxonomy for learning. teaching. and assessing: a revision of bloom's taxonomy of educational objectives. New York: Longman.

Australlian Psychology Accreditation Council (APAC). (2010). Rules \& accreditation standards for psychology courses. Finders Lane: APAC.

Ballado. R.S.. Morales. R.A.. \& Ortiz. R.M. (2014). Development and validation 


\section{Aptitude Test's Predictive Ability \\ Farida Agus Setiawati}

of a teacher education aptitude test. International Journal of Interdisciplinary Research and Innovations. 2 (4) 129133.

Bennett. G. K.. Seashore. H. G.. \& Wesman. A. G. (1948). Differential Aptitude Tests. Journal of Consulting Psychology. 12. 62.

Curabay. M. (2016). Meta-analysis of the predictive validity of scholastic aptitude test (SAT) and american college testing (ACT) scores for college GPA. Thesis. Denver: University of Denver.

$D A T$ for Selection General Abilites Battery: Technical Manual and User Guide. (2013). London: Pearson Education Ltd. ISBN 978074910454.

Dev. M. (2016). Factors affecting the academic achievement: a study of elementary school students of NCR delhi. india. Journal of Education and Practice. 7 (4). 70-74.

Fraser. W.J.. \& Killen. R. (2003). Factors influencing academic success or failure of first-year and senior university students: do education students and lecturers perceive things differently?. South African Journal of Education. 23 (4). 254-260.

Gronlund. N. E. (1981). Measurement and evaluation in teaching. New York Macmillan Publishing Co.

Hijazi. S.Y.. \& Naqvi. S. M. M. R. (2006). Factors affecting students' performance: a case of private colleges. Bangladesh e-Journal of Sociology. 3 (1). 1-10.

Linn. R. L. (1984). Ability testing: individual differences. prediction. and differential prediction. Dalam A. K. Widgor \& W. R. Garner (Eds.). Ability testing: uses. concequences. and controversies (Part II). Washington DC: National Academy Press.
Mankar. J.. \& Chavan. D. (2013). Differential aptitude testing of youth. International Journal of Scientific and Research Public. 3 (7). 1-6.

Marais. A. C. (2007). Using the differential aptitude test to estimate intellegence and scholastic achievement at grade nine level. Thesis. Pretoria: University South Africa.

Mardapi. D. (2007). Teknik penyusunan instrumen tes dan nontes. Yogyakarta: Mitra Cendekia.

New Zealand Psycologists Board. (2011). Core competencies for the practice of psychology in new realand. Wellington: New Zealand Psychological Society.

Nijenhuis. J.T.. Evers. A.. \& Mur. J.P. (2000). Validity of the differential aptitude test for the assessment of immigrant children. An International Journal of Experimental Educational Psychology. 20 (1). 99-115.

Nunnaly. J. C. (1970). Introduction to psychological measurement. Tokyo: Kogakusha company. Ltd.

Pearson Assessment. (2009) The differential aptitude test. Report for simon sample. Upper Sadle River: Pearson Education.

Raza. M.A.. \& Shah. A.F. (2009). The impact of parents' education towards the science aptitude of the students at elemtary level in southern punjab. Pakistan Journal of Social Sciences. 29 (1). 117-125.

Raza. M.A.. \& Shah. A.F. (2011). Impact of favourite subject towards the scientific aptitude of the students at elementary level. Pakistan Journal of Social Sciences. 31 (1). 135-143.

Ruth. A. (1971). A study of the predictability of high school grades and the differential aptitude tests for success in vocational programs in 


\section{Aptitude Test's Predictive Ability \\ Farida Agus Setiawati}

health careers. Thesis. Wisconsin:

Wisconsin University.

Santosa. A. B. (2013). Seleksi Calon

Mahasiswa Baru terhadap Kualitas

Lulusan. Cakrawala Pendidikan. 16

(1). 51-57.

Sax. G. (1980). Principles of educational and psychological measurement and evaluation. Belmont: Wardsworth Publication Company. Inc.

Shea. D. L.. Lubinski. D.. \& Benbow. C.P. (2001). Importance of assessing spatial ability in intelectually talented young adolescents: a 20-year longitudinal study. Journal of Educational Psychology. 93 (3). 604614.

Stickler. L. (2007). A critical review of the SAT: menace or mild-mannered measure?. The College of New Jersey. Journal of Student Scholarship. 9. 1-9.

Sudarmanto. R.G. (2005). Analisis Regresi Linear dengan SPSS. Yogyakarta: Graha Ilmu.

Young. J. W. (2001). Differential validity. differential prediction. and college admission testing: a comprehensive review and analysis. Research Report No.2001-6. New York: College Entrance Examination Board. 